\section{Improvements Following an Easy and Inexpensive Quality Assurance Program on the Usage of Antibiotics In the Emergency Room Setting}

\section{To the Editor:}

In the United States over 180 million prescriptions for antibiotics are filled each year; they represent the most commonly prescribed drugs. ${ }^{1}$ The vast majority of studies evaluating the appropriateness of antibiotic usage have been conducted on hospital inpatients, but few in an outpatient setting. ${ }^{1-3}$ This lack of surveillance leads to unnecessary therapy, poor drug choice, misguided prophylaxis, and inordinate cost to the health care system.

We conducted a study on antibiotic usage in our Community Hospital Emergency Room. The records of our Emergency Department were retrospectively reviewed on two separate, random occasions. All cases in which the diagnosis was an infectious disease or an antibiotic was prescribed are included in the study.

A baseline audit of 200 consecutive charts were reviewed from August 1- 3, 1985. Forty-four patients $(22 \%)$ received antibiotics. Prophylactic antibiotics were prescribed to 14 patients
(32\%) (superficial wounds of hands and feet treated with penicillin or its derivative, or an oral cephalosporin). Inappropriate antibiotics were prescribed to five patients (11\%) (viral syndrome [ 3 cases], uninfected herpes zoster, tetracycline to treat Group A beta hemolytic tonsillo-pharyngitis). Appropriate antibiotics were prescribed to the remaining 25 cases (57\%) (bronchitis with penicillin or its derivative, or an oral cephalosporin; tonsillo-pharyngitis with penicillin or its derivative; otitis media with penicillin or its derivative; urethritis and pelvic inflammatory disease with doxycycline; urinary tract infection with trimethoprim-sulfamethoxazole or penicillin derivatives; and diverticulitis with penicillin derivatives). Of these 25 cases, it was necessary to culture 20 patients $(46 \%)$ (tonsillopharyngitis, urethritis, urinary tract infection, and pelvic inflammatory disease). Actually only one patient was cultured.

A Quality Assurance Program was then formulated in an attempt to modify physician prescribing patterns and increase appropriate culturing. A novel antibiotic prescription form devised by a Massachusetts group (Durbin, et al) was modified by us into a stamp. ${ }^{4}$ Obligatory use of this antibiotic stamp required physicians to categorize antibiotic use as either prophylactic, empirical, or therapeutic. In-service educational sessions stressed that in each clinical situation the optimal use of an antibiotic depends upon consideration of efficacy, safety, acceptability, cost, and culturing when appropriate prior to use.

A follow-up audit of 260 consecutive charts was conducted six months later, March 3-5, 1986. Fifty-two patients $(20 \%)$ received antibiotics. Prophylactic antibiotics were prescribed to 10 patients $(19 \%)$ (superficial wounds of hands and feet with penicillin or its derivative, or with an oral cephalosporin). Inappropriate antibiotics were prescribed to three patients $(6 \%)$ (for viral syndrome). Appropriate antibiotics were prescribed to the remaining 39 patients (75\%) (bronchitis with penicillin or its derivative tetracycline or erythromycin; tonsillopharyngitis with penicillin or its derivative, or erythromycin; otitis media with penicillin or its derivative or an oral cephalosporin; urethritis and pelvic inflammatory disease with penicillin or its derivative, erythromycin, or an oral cephalosporin; urinary tract infection with trimethoprim-sulfamethoxazole or penicillin deriva. tives; and lobar pneumonia with erythromycin). Of these 39 cases, it was necessary to culture 21 patients (40\%) (tonsillo-pharyngitis, urethritis, urinary tract infection, pelvic inflammatory disease). This time eight patients $(38 \%)$ were cultured. There was $100 \%$ compliance with the antibiotic stamp.

Comparing the two audits, there was an almost $50 \%$ decrease in inappropriate antibiotic use with a con comitant improvement in appropriate continued on page 184 


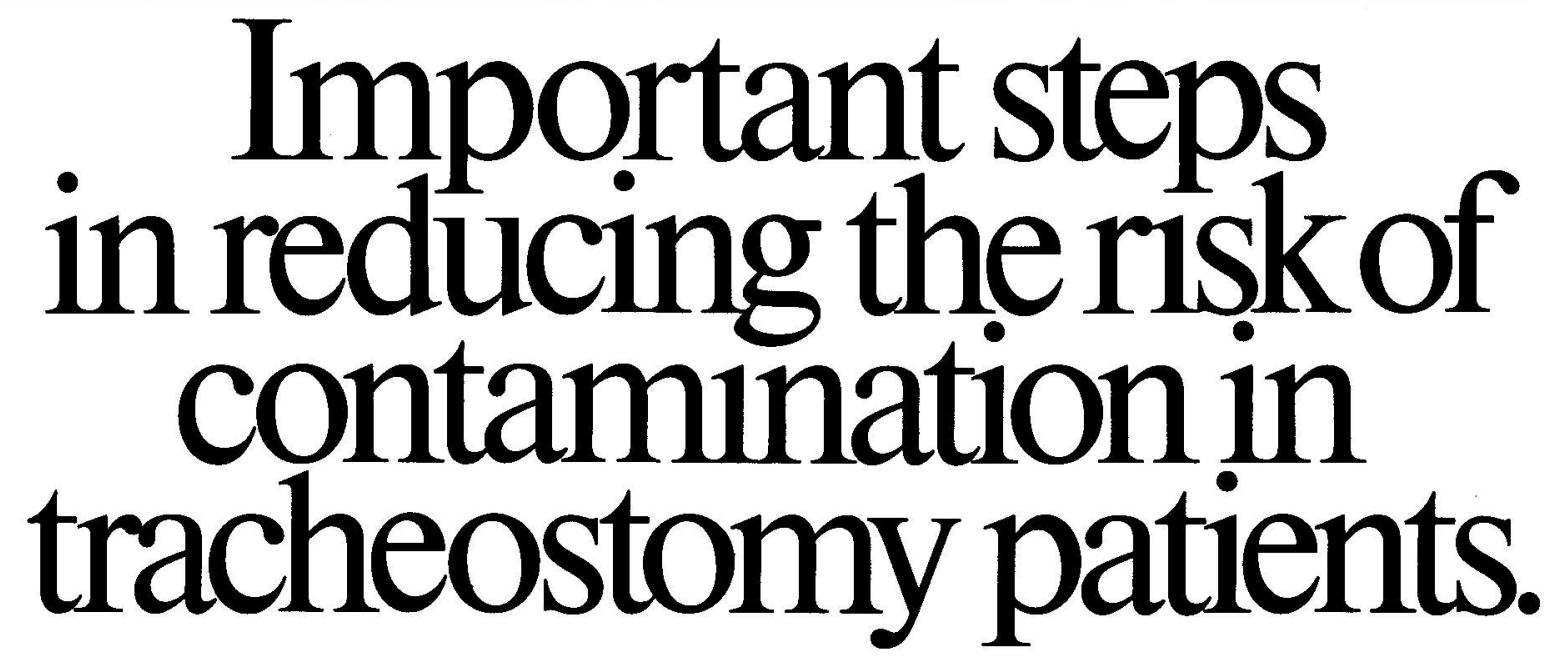

7 hrow contamination away! That's what every health care professional wants to do in treating tracheostomy patients. And that desire is closer to reality with Shiley's Disposable Inner Cannula (DIC) system of tracheostomy tubes.

Since the DIC was first introduced, doctors, nurses and therapists have accepted it as a significant advance in reducing the risk of contamination and infection, as well as a time and cost saver.' Tracheostomy care procedures can be simplified and trach care kits can be eliminated.

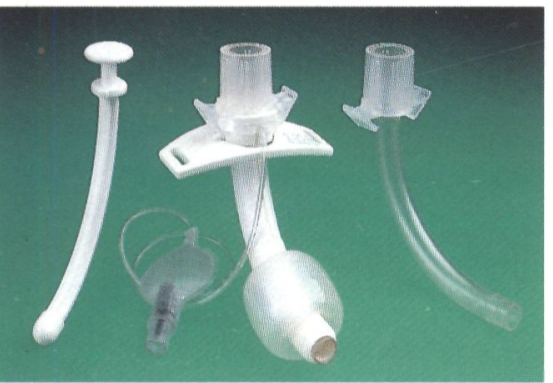

DIC is used with all

Shiley disposable cannula tracheostomy tubes.

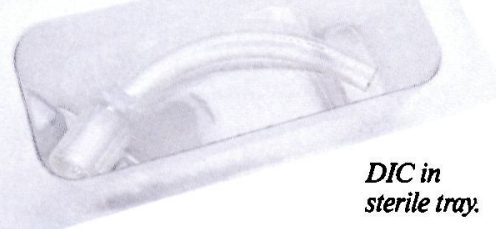

To realize the benefits of the disposable inner cannula, the health care professional simply needs to follow these four important steps:

Step 1-Remove the used inner cannula, employing aseptic procedures, by firmly pinching the clamps of the snap-lock connector and gently pulling back from the tracheostomy tube. The professional should note the size of the tube for correct DIC replacement.

Step 2-Important! After determining that the inner cannula is indeed a disposable type (and not a reusable inner cannula with a twist lock), discard the DIC in an appropriate disposal container. Remember, do not clean, resterilize, or reuse the DIC.

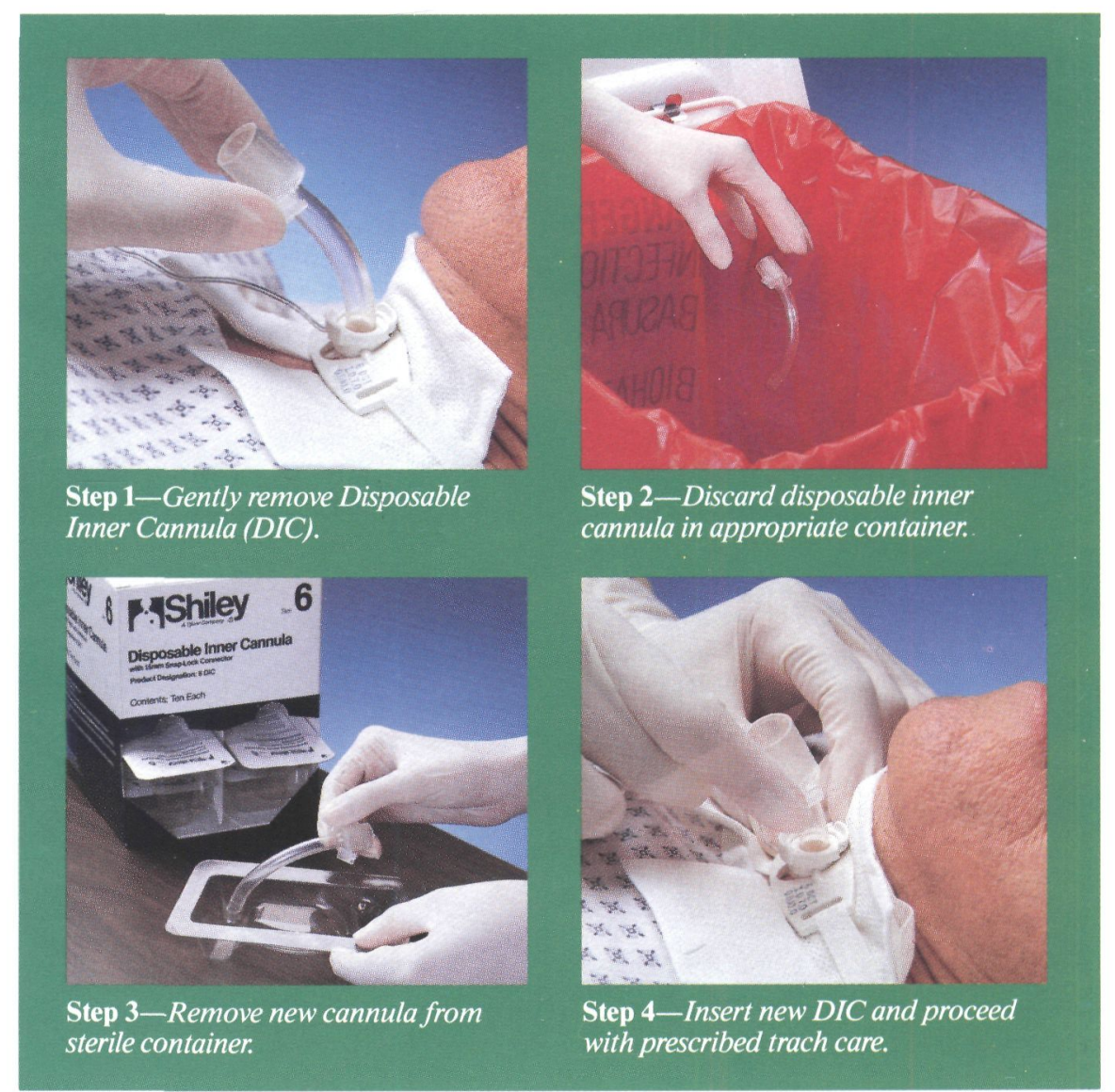

Step 3-Remove the correct size DIC from its sterile container by the pinch clamps of the snap-lock connector using aseptic technique.

Step 4-Still using aseptic technique, insert the new DIC, securely snapping both sides of the connector, and proceed with hospital-prescribed trach care. The sterile tray from the DIC makes a convenient basin for stoma care.

So, take a big step in reducing the risk of contamination and infection-by throwing away the used disposable inner cannula. For more information, and for details on our informative video program about tracheostomy care, contact your Shiley Technical Representative at (800) 233-8969 or write to Shiley Incorporated, 17600 Gillette Avenue, Irvine, CA $92714-5751$ U.S.A., Tel: (714) 250-
0500, (800) 854-3683, Cable: SHILEYINC IRIN, Telex: 68-5585. Shiley-Europe, Staines House, 158-162 High Street, Staines, TW18 4AZ, ENGLAND, Tel: (44) 78461533, Telex: 919851 PFHPGS-G. Shiley Canada, 251 Bartley Drive, Toronto, Ontario, M4A-2N7 CANADA, Tel: (416) 752-9990, Telex: 06963811.

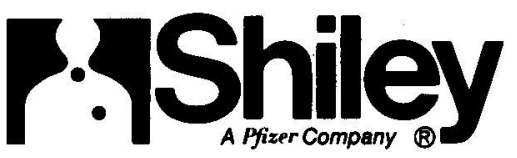

1Sue Crow, RN, MSN, "Disposable Tracheostomy Inner Cannula," Infection Control, Vol. 7, No. 5, 1986, pp. 285-286.

For detailed information describing intended use, warnings, precautions and contraindications, refer to the instructions provided with each device or contact the Shiley corporate office. (C) Shiley Incorporated, 1987. All rights reserved. 086R P211 (1/87) 
continued from page 182

usage. Furthermore, the incidence of appropriate culturing increased from $5 \%$ to $38 \%$, a better than sevenfold increase.

We conclude that through an easy and inexpensive Quality Assurance Program comprised of in-service educational sessions, simple audit, and the use of a novel antibiotic stamp, the physician's consciousness can be raised to apply sound principles in the usage of antibiotics and culture. The result is an increase in appropriate antibiotic use and prior culturing when needed. The benefit is to the patient through an augmented quality of care and to the health care system through elimination of unnecessary and excessive cost.

\section{REFERENCES}

1. Bernstein LR, Barriere SL, Conte JE: Utilization of antibiotics: Analysis of appropriateness of use. Ann Emerg Med 1982; $11: 8$.

2. Siegel D, Sande MA: Patterns of antibiotic use in a busy metropolitan emergency room. West / Med 1983 ; metropolitan

3. Stamps P, Kirk J, et al: Use of antibiotics in primary care. QRB July 1982; 16-21.

4. Durbin WA, Lapidas B, Goldmann DA: Improved antibiotic usage following introduction of a novel prescription system. JAMA 1981; 246(16):1796-1800.

Frank V. Porco, MD Pascal J. de Caprariis, MD Virginia Anderson, MD Enriqueta C. Leong, MD Ernest B. Visconti, MD Department of Ambulatory Services Emergency Service and Infectious Disease Section Lutheran Medical Center Brooklyn, New York

\section{Corrections in November Brief Report}

The Editor apologizes for the following errors which occurred in the Brief Report "Influence of Country of Markers Among Employees in a Small Origin on Prevalence of Hepatitis B

Suburban Hospital" by Frank W. Kiel, MD, November 1986, pp. 554-557. In addition, the Editor regrets any inconvenience these errors may have caused the author or the reader.

\begin{tabular}{|c|c|c|}
\hline ITEM & AS PRINTED & SHOULD HAVE BEEN \\
\hline Abstract, Line 8-10. & $\begin{array}{l}\text { Foreign-born } \\
\text { participants } \\
\text { accounted for } 68 \% \\
\text { of the employee } \\
\text { population. }\end{array}$ & $\begin{array}{l}\text { Foreign-born participants accounted for } \\
68 \% \text { of the positive marker cases while } \\
\text { representing only } 31 \% \text { of the employee } \\
\text { population. }\end{array}$ \\
\hline Results, para 2 line 5 & $P>0.001$ & $P=0.001$ or $P<0.001$ \\
\hline $\begin{array}{l}\text { Table } 1 \\
\text { Subtitles, Col } 7\end{array}$ & HAV & HAVt \\
\hline $\begin{array}{l}\text { Table 1, Low-Risk } \\
\text { Subtotal, Col } 1\end{array}$ & 71 & 74 \\
\hline $\begin{array}{l}\text { Table 1, Mid-Risk, } \\
\text { Subtotal line }\end{array}$ & Missing & $107,25,66,9,41,16,54$ \\
\hline $\begin{array}{l}\text { Table 1. High-Risk, } \\
\text { Intensive Care Unit, } \\
\text { Col } 4\end{array}$ & 2 & 0 \\
\hline $\begin{array}{l}\text { Low-Risk, Dietary } \\
\text { Service, Col } 6\end{array}$ & $* *$ & $\S$ \\
\hline $\begin{array}{l}\text { Table 1, High-Risk, } \\
\text { Intensive Care Unit, } \\
\text { Col } 6\end{array}$ & No $\S$ & $\S$ \\
\hline $\begin{array}{l}\text { Table 2, Central } \\
\text { America, Col } 2\end{array}$ & 1 & 0 \\
\hline
\end{tabular}




\section{Merck Sharp \& Dohme Research Laboratories... Unlocking the potential of DNA}

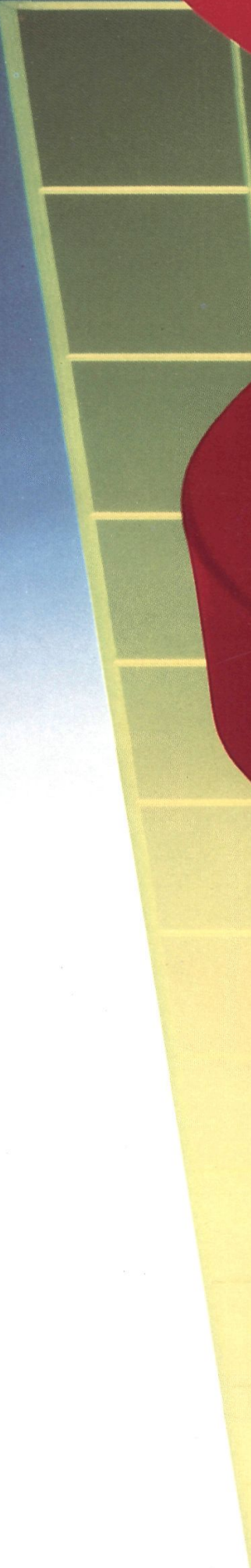

For a Brief Summary of Prescribing Information for

RECOMBIVAX-HBं ${ }^{\circledR}$ (Hepatitis B Vaccine [Recombinant],

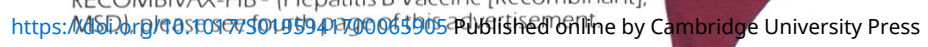




\section{Introducing New}

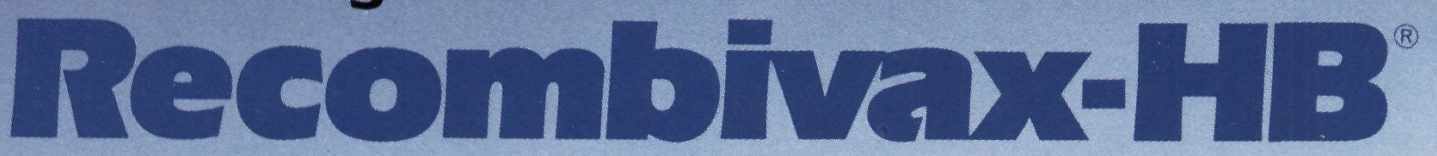

(Hepatitis B Vaccine [Recombinant]|MSD) The first genetically designed vaccine for humans

\section{Another choice}

\section{To help prevent hepatitis B in those at increased risk}

- Derived from yeast by means of advanced biotechnology (not derived from plasma)

- Produces a protective antibody comparable to that of HEPTAVAX-B ${ }^{\infty}$ (Hepatitis B Vaccine, MSD)

- Provides an alternative to vaccination with HEPTAVAX-B 


\section{Another chance}

\section{To help protect yourself... your family... and your career}

- Against contracting and transmitting hepatitis B, a potentially serious disease

- Against developing an irreversible chronic-carrier state

\section{To help protect your institution}

- Against the costs of accidental exposure

- Against the devastation of a hepatitis B outbreak

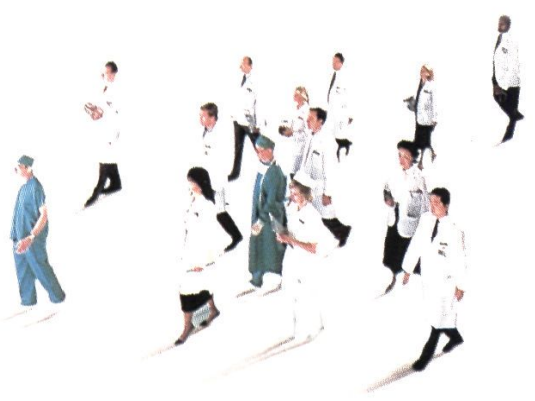

Because of the long incubation period for hepatitis $B$, it is possible for unrecognized infection to be present at the time HEPTAVAX- $B^{\circledR}$ (Hepatitis B Vaccine, MSD) or RECOMBIVAX-HB ${ }^{\circledast}$ (Hepatitis B Vaccine [Recombinant], MSD) is given. HEPTAVAX-B or RECOMBIVAX-HB may not prevent hepatitis B in such patients.

For a Brief Summary of Prescribing Information for RECOMBIVAX-HB, please see following page. For a Brief Summary of Prescribing Information for HEPTAVAX-B, please see last page of this advertisement. 


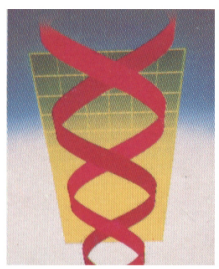

Recombivax-HB'

(Hepatitis B Vaccine [Recombinant] |MSD)

INDICATIONS AND USAGE

RECOMBIVAX-HB is indicated for immunization against infection caused by all

known subtypes of hepatitis $B$ virus.

RECOMBIVAX-HB will not prevent hepatitis caused by other agents, such as hepatitis A virus, non-A non-B hepatitis viruses, or other viruses known to infect the liver.

Vaccination is recommended in persons of all ages who are or will be at increased risk of infection with hepatitis B virus. In areas with high prevalence of infection most of the population are at risk of acquiring hepatitis B infection at a young age.

Therefore, vaccination should be targeted to prevent such transmission. In areas of low prevalence, vaccination should be limited to those who are in groups identified as being at increased risk of infection.

CONTRAINDICATIONS

Hypersensitivity to yeast or any component of the vaccine.

\section{WARNINGS}

Patients who develop symptoms suggestive of hypersensitivity after an injection should not receive further injections of RECOMBIVAX-HB (see CONTRAINDICATIONS)

Because of the long incubation period for hepatitis B, it is possible for unrecognized infection to be present at the time RECOMBIVAX-HB is given. RECOMBIVAXHB may not prevent hepatitis $B$ in such patients.

\section{PRECAUTIONS}

\section{General}

As with any percutaneous vaccine, epinephrine should be available for immediate use should an anaphylactoid reaction occur.

Any serious active infection is reason for delaying use of RECOMBIVAX-HB except when in the opinion of the physician, withholding the vaccine entails a greater risk.

Caution and appropriate care should be exercised in administering RECOMBIVAX$H B$ to individuals with severely compromised cardiopulmonary status or to others in whom a febrile or systemic reaction could pose a significant risk.

\section{Pregnancy}

Pregnancy Category C. Animal reproduction studies have not been conducted with RECOMBIVAX-HB. It is also not known whether RECOMBIVAX-HB can cause fetal harm when administered to a pregnant woman or can affect reproduction capacity. RECOMBIVAX-HB should be given to a pregnant woman only if clearly needed.

\section{Nursing Mothers}

It is not known whether RECOMBIVAX$H B$ is excreted in human milk. Because many drugs are excreted in human milk. caution should be exercised when RECOMBIVAX-HB is administered to a nursing woman.

\section{Pediatric Use}

RECOMBIVAX-HB has been shown to be usually well tolerated and highly immuno-
(Hepatitis B Vaccine [Recombinant], MSD) genic in infants and children of all ages. Newborns also respond well; maternally transferred antibodies do not interfere with the active immune response to the vaccine. SEe DOSAGE AND ADMINISTRATION for recommended pediatric dosage and for recommended dosage for infants born to HBsAg positive mothers

\section{ADVERSE REACTIONS}

RECOMBIVAX-HB is generally well tolerated. No serious adverse reactions attributable to the vaccine have been reported during the course of clinical trials. No serious hypersensitivity reactions have been reported. No adverse experiences were reported during clinical trials which could be related to changes in the titers of antibodies to yeast. As with any vaccine, there is the possibility that broad use of the vaccine could reveal adverse reactions not observed in clinical trials.

In a group of studies, 3258 doses of vaccine were administered to 1252 healthy adults who were monitored for 5 days after each dose. Injection site and systemic complaints were reported following $17 \%$ and

$15 \%$ of the injections, respectively.

The following adverse reactions were reported:

Incidence Equal to or Greater than $1 \%$ of Injections

LOCAL REACTION (INJECTION SITE)

Injection site reactions consisting principally of soreness and including pain, tenderness, pruritus, erythema, ecchymosis, swelling. warmth and nodule formation.

\section{BODY AS A WHOLE}

The most frequent systemic complaints include fatigue/weakness; headache; fever $\geqslant 100^{\circ} \mathrm{Fl}$; malaise.

DIGESTIVE SYSTEM

Nausea; diarrhea.

RESPIRATORY SYSTEM

Pharyngitis; upper respiratory infection. Incidence Less than $1 \%$ of injections BODY AS A WHOLE

Sweating; achiness; sensation of warmth: lightheadedness; chills; flushing.

DIGESTIVE SYSTEM

Vomiting; abdominal pains/cramps; dyspepsia: diminished appetite.

RESPIRATORY SYSTEM

Rhinitis; influenza; cough

NERVOUS SYSTEM

Vertigo/dizziness; paresthesia.

INTEGUMENTARY SYSTEM

Pruritus; rash (non-specified); angioedema; urticaria.

\section{MUSCULOSKELETAL SYSTEM}

Arthralgia including monoarticular; myal-

gia; back pain; neck pain; shoulder pain;

neck stiffness.

HEMIC/LYMPHATIC SYSTEM

Lymphadenopathy.

PSYCHIATRIC/BEHAVIORAL

Insomnia/disturbed sleep.

SPECIAL SENSES

Earache.

UROGENITAL SYSTEM

Dysuria.

CARDIOVASCUIAR SYSTEM

Hypotension

Potential ADVERSE EFFECTS

In addition, a variety of adverse effects, not observed in clinical trials with RECOMBIVAX-HB have been reported with HEPTAVAX-B ${ }^{\circledR}$ (Hepatitis B Vaccine, MSD) (plasma-derived hepatitis B vaccine) Those listed below are to serve as alerting information to physicians:

Hypersensitivity: An apparent hypersensi-

tivity syndrome of delayed onset has been
RECOMBIVAX-HB

Hepatitis B Vaccine [Recombinant]. MSD

reported days to weeks after vaccination. This has included the following findings: arthritis (usually transient), fever, and dermatologic reactions such as urticaria, erythema multiforme, or ecchymoses. Nervous System: Neurological disorders such as optic neuritis, myelitis including transverse myelitis; acute radiculoneuropathy including Guillain-Barré syndrome: peripheral neuropathy including Bell's

palsy and herpes zoster.

Hematologic: Thrombocytopenia. Special Senses: Tinnitus; visual disturbances.

\section{DOSAGE AND ADMINISTRATION}

Do not inject intravenously or intradermally.

RECOMBIVAX-HB is for intramuscular injection. The deltoid muscle is the preferred site for intramuscular injection in adults. Data suggest that injections given in the buttocks frequently are given into fatty tissue instead of into muscle. Such injec tions have resulted in a lower seroconversion rate than was expected. The anterolateral thigh is the recommended site for intramuscular injection in infants and young children.

RECOMBIVAX-HB may be administered subcutaneously to persons at risk of hemorrhage following intramuscular injections. However, when other aluminum-adsorbed vaccines have been administered subcutaneously, an increased incidence of local reactions including subcutaneous nodules has been observed. Therefore, subcutaneous administration should be used only in persons (e.g., hemophiliacs) at risk of hemorrhage following intramuscular injections.

The immunization regimen consists of 3 doses of vaccine. The volume of vaccine to be given on each occasion is as follows:

\begin{tabular}{|l|l|lll|}
\hline Group & Formulation & Initial & 1 month & $6 \mathrm{months}$ \\
\hline $\begin{array}{l}\text { Younger Children } \\
\text { (Birth to 10 } \\
\text { years of age) }\end{array}$ & $\begin{array}{l}\text { Pediatric } \\
5 \mathrm{mcg} / 0.5 \mathrm{~mL}\end{array}$ & $0.5 \mathrm{~mL}$ & $0.5 \mathrm{~mL}$ & $0.5 \mathrm{~mL}$ \\
\hline $\begin{array}{l}\text { Adults and Older } \\
\text { Children }\end{array}$ & $\begin{array}{l}\text { Adult } \\
10 \mathrm{mcg} / 1.0 \mathrm{~mL}\end{array}$ & $1.0 \mathrm{~mL}$ & $1.0 \mathrm{~mL}$ & $1.0 \mathrm{~mL}$ \\
\hline
\end{tabular}

Since there have been no clinical studies in which a vaccine series was initiated with HEPTAVAX-B ${ }^{\circledR}$ (Hepatitis B Vaccine, MSD) and completed with RECOMBIVAX-HB, or vice verşa, it is recommended that the 3-dose series be completed with the same vaccine that was used for the initial dose.

Whenever revaccination or administration of a booster dose is appropriate, RECOMBIVAX-HB may be used.

For dosage for infants born of $\mathrm{HBSAg}$ positive mothers and for dosage for known or presumed exposure to HBsAg, see the Prescribing Information.

The vaccine should be used as supplied; no dilution or reconstitution is necessary. The full recommended dose of the vaccine should be used.

Storage

Store vials at $2-8^{\circ} \mathrm{C}\left|35.6-46.4^{\circ} \mathrm{F}\right|$. Storage above or below the recommended temperature may reduce potency.

Do not freeze since freezing destroys potency.

For more detailed information, consult
your MSD Representative or see Pre--
scribing Information. Merck Sharp \&
Dohme, Division of Merck \& Co., INC.,
West Point, PA 19486.
[200




\section{Make a choice... Don't take a chance}

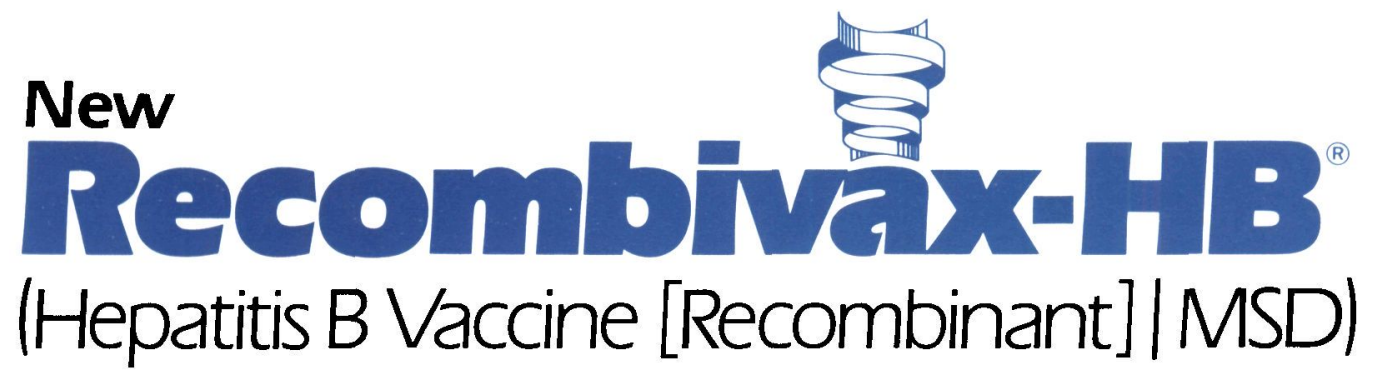

Also available
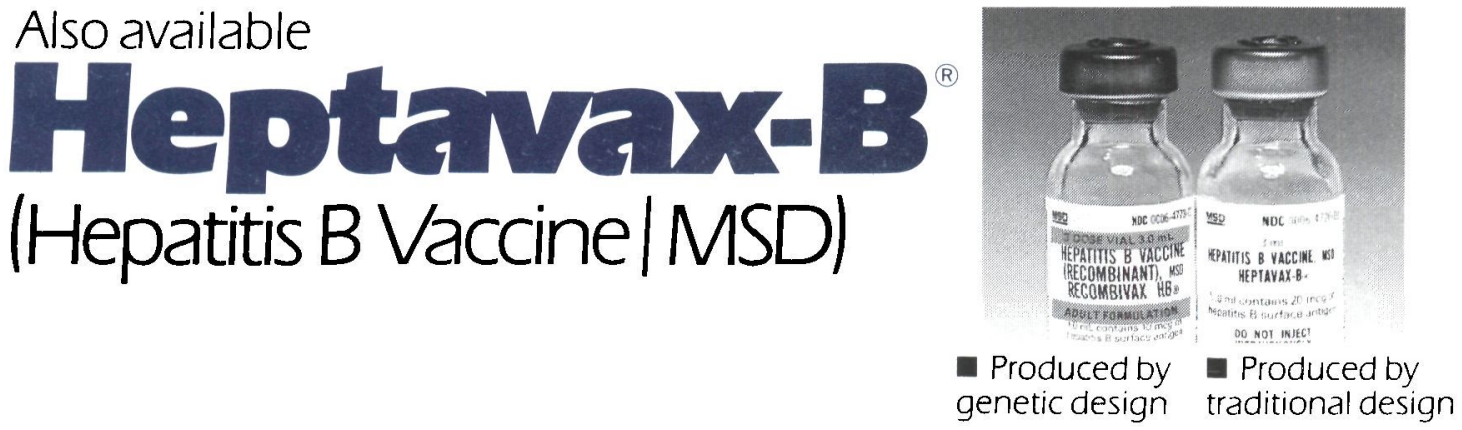

\section{BOTH}

are highly effective against hepatitis $B$ and help prevent its many potential complications and sequelae.

\section{BOTH}

provide highly effective protection for the health-care professional, thereby protecting against possible transmission to family members.

\section{BOTH}

help protect against becoming a chronic carrier and the potential devastating effect on a health-care career.

\section{BOTH}

help protect hospitals against the costly occurrence of a hepatitis B outbreak. 
Heptavax- B $^{\circ}$

(Hepatitis B Vaccine/MSD)

INDICATIONS AND USAGE

HEPTAVAX-B is indicated for immunization against infection caused by all known subtypes of hepatitis $B$ virus

HEPTAVAX-B will not prevent hepatitis caused by other agents, such as hepatitis A virus, non-A non-B hepatitis viruses, or other viruses known to infect the liver.

Vaccination is recommended in persons of all ages, especially those who are or will be at increased risk of infection with hepatitis $B$ virus.

\section{CONTRAINDICATIONS}

Hypersensitivity to any component of the vaccine.

\section{WARNINGS}

Persons with immunodeficiency or those receiving immunosuppressive therapy require larger vaccine doses and respond less well than do healthy individuals.

Because of the long incubation period for hepatitis $B$, it is possible for unrecognized infection to be present at the time HEPTAVAX-B is given. HEPTAVAX-B may not prevent hepatitis $B$ in such patients. Patients who develop symptoms suggestive of hypersensitivity after an injection should not receive further injections of HEPTAVAX-B.

\section{PRECAUTIONS}

\section{General}

As with any parenteral vaccine, epinephrine should be available for immediate use should an anaphylactoid reaction occur. Any serious active infection is reason for delaying use of this vaccine except when, in the opinion of the physician, withholding the vaccine entails a greater risk. Caution and appropriate care should be exercised in administering this vaccine to individuals with severely compromised cardiopulmonary status or to others in whom a febrile or systemic reaction could pose a significant risk.

\section{Pregnancy}

Pregnancy Category C. It is not known whether the vaccine can cause fetal harm when administered to pregnant women or can affect reproductive capacity. The vaccine should be given to a pregnant woman only if clearly needed.

\section{Nursing Mothers}

Studies in 12 lactating women have failed to reveal evidence of this vaccine being secreted in breast milk.

\section{Pediatric Use}

This vaccine has been shown to be well tolerated and highly immunogenic in infants and children of all ages. Newborns also respond well: maternally transferred antibodies do not interfere with the active immune response to the vaccine. See DOSAGE AND ADMINISTRATION section in Prescribing Information for recommended pediatric dosage and for recommended dosage for infants born to HBsAg positive mothers.

\section{ADVERSE REACTIONS}

HEPTAVAX-B is generally well tolerated. No serious adverse reactions attributable to vaccination were reported during the course of clinical trials involving administration of HEPTAVAX-B to over 19,000 individ-
HEPTAVAX-B
(Hepatitis B Vaccine,
(HSD)

uals. As with any vaccine, there is the possibility that broad use of the vaccine could reveal rare adverse reactions not observed in clinical trials. In three double blind placebo-controlled studies among 3,350 persons, the overall rates of adverse reactions reported by vaccine recipients $(24.3 \%, 21.5 \%$, and $22.8 \%)$ did not differ significantly from those of placebo recipients $(21.4 \%, 18.7 \%$, and $21.9 \%)$. Approximately half of all reported reactions were injection-site soreness, which occurred somewhat more frequently among vaccine recipients.

In another group of studies, 3,516 doses of vaccine were administered to 1,255 healthy adults. Vaccinees were monitored for 5 days after each dose, and the following adverse reactions were reported:

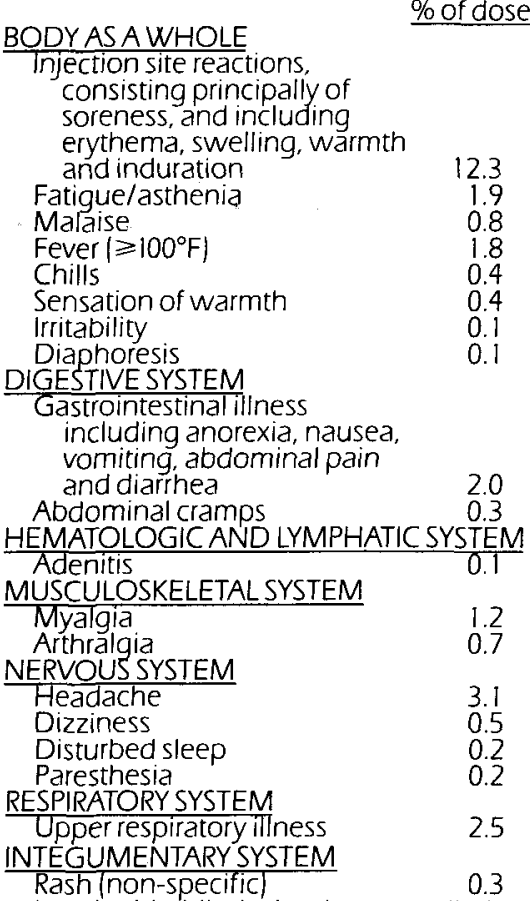

In a double-blind, placebo-controlled. clinical trial of 1,330 health-care workers, the frequency of elevations in SGPT (ALT) in vaccine recipients was not significantly different from that in placebo recipients. In marketed use of the vaccine, non-specific abnormalities in SGPT (ALT) and other liver function tests have been reported, but no causal relationship has been established. The following additional adverse reactions have been reported with use of the marketed vaccine.

Hypersensitivity Reaction

symptoms of immediate hypersensitivity including urticaria, angioedema, and pruritus have been reported rarely within the first few hours after vaccination. An apparent hypersensitivity syndrome of delayed onset has been reported rarely, days to weeks after vaccination. This has included the following findings: arthritis (usually transient), fever, and dermatologic reactions such as urticaria, erythema multiforme, or ecchymoses. Nervous System

Neurological disorders such as: optic neuritis: myelitis, including transverse myelitis: acute radiculoneuropathy, including Guillain-Barré syndrome; peripheral neuropathy, including Bell's palsy and herpes zoster

Hematologic

Thrombocytopenia.

\section{HEPTAVAX-B ${ }^{\circledR}$}

(Hepatitis B Vaccine, MSD)

Special Senses

Tinnitus, visual disturbances.

Integumentary System

Flushing.

DOSAGE AND ADMINISTRATION

Do not inject intravenously or

intradermally.

HEPTAVAX-B is for intramuscular injection. The deltoid muscle is the preferred site for intramuscular injection in adults. Data

suggest that injections given in the buttocks frequently are given into fatty tissue instead of into muscle. Such injections may result in a lower seroconversion rate than is

expected. The anterolateral thigh is the recommended site for intramuscular injection in infants and children.

HEPTAVAX-B may be administered subcutaneously to persons at risk of hemorthage following intramuscular injections The immune responses and clinical reactions following intramuscular and subcutaneous administration of HEPTAVAX-B have been shown to be comparable. However, when other aluminum-adsorbed vaccines have been administered subcutaneously, an increased incidence of local reactions including subcutaneous nodules has been observed. Therefore, subcutaneous administration should be used only in persons (e.g., hemophiliacs) at risk of hemorrhage following intramuscular injections.

Shake well before withdrawal and use.

Thorough agitation at the time of administration is necessary to maintain suspension of the vaccine.

Parenteral drug products should be inspected visually for particulate matter and discoloration prior to administration.

The immunization regimen consists of 3 doses of vaccine. The volume of vaccine to be given on each occasion is as follows:

\begin{tabular}{|c|c|c|c|c|}
\hline Group & Formulation & Iritial & imonth & 6 months \\
\hline $\begin{array}{l}\text { Younger Children } \\
\text { Birth to } 10 \\
\text { years of agel }\end{array}$ & $\begin{array}{l}\text { Pediattic } \\
10 \mathrm{meg} / 0.5 \mathrm{~mL}\end{array}$ & $0.5 \mathrm{~mL}$ & $0.5 \mathrm{~mL}$ & $0.5 \mathrm{~mL}$ \\
\hline $\begin{array}{l}\text { Adults and Older } \\
\text { Children }\end{array}$ & $\begin{array}{l}\text { Adult } \\
20 \mathrm{mcg} / 1.0 \mathrm{~mL}\end{array}$ & $1.0 \mathrm{~mL}$ & $1.0 \mathrm{~mL}$ & $1.0 \mathrm{ml}$ \\
\hline $\begin{array}{l}\text { Dialysis Patients } \\
\text { and Immuno- } \\
\text { compromised } \\
\text { Patients }\end{array}$ & $\begin{array}{l}\text { Adult } \\
20 \mathrm{mcg} / 1.0 \mathrm{~mL}\end{array}$ & $2.0 \mathrm{~mL} *$ & $2.0 \mathrm{~mL}^{*}$ & $2.0 \mathrm{~mL}^{*}$ \\
\hline
\end{tabular}

For dosage for infants born of HBsAg positive mothers and for dosage for known or presumed exposure to HBsAg, see the

Prescribing Information

The vaccine should be used as supplied: no dilution or reconstitution is necessary. The full recommended dose of the vaccine should be used.

Storage

Store vials at $2-8^{\circ} \mathrm{C}\left(35.6-46.4^{\circ} \mathrm{F}\right)$ Storage above or below the recommended temperature may reduce potency.

Do not freeze since freezing destroys potency.

For more detailed information, consult your MSD Representative or see Prescribing Information. Merck Sharp \& Dohme, Division of Merck \& Co., INC. West Point, PA 19486. 